\title{
Digital Marketing: Problems of Internet Pharmacies Legal Regulation
}

\author{
Ph.D. Vitalii Pashkov \\ ORCID: 0000-0001-9489-7768 \\ Department of Civil, Commercial and Environmental Law, \\ Poltava Law Institute, Ukraine \\ Laboratory for the Study of National Security Problems \\ in the Field of Public Health, Ukraine \\ v.pashkov26.06@ukr.net \\ Dr. med. Oleksii Soloviov \\ ORCID: 0000-0002-6615-4868 \\ National Security and Defense Council of Ukraine \\ Ph.D. Andrii Harkusha \\ ORCID: 0000-0001-5266-3007 \\ Department of Civil, Commercial and Environmental Law, \\ Poltava Law Institute, Ukraine \\ Laboratory for the Study of National Security Problems \\ in the Field of Public Health, Ukraine \\ andreigarkusha@gmail.com
}

\section{Abstract}

Digitalisation of pharmaceutical activities is creating a new type of pharmaceutical market, a more flexible and less costly; yet it has become more dangerous for patients and the economic stability. The reason is the imperfection of the legal regulation and online sales of pharmaceutical products, in particular. It is necessary to clarify that digitalisation of pharmaceutical activities is not only about online sales of pharmaceutical products. It is also digital marketing, which includes promoting pharmaceutical products via the Internet, including advertising such products. Research shows that prescription drugs are sold to such patients by both illegal online pharmacies and legal ones. Most counterfeit medicines are sold through illegal online pharmacies.

The purpose of the article is to draw attention to the need for legal support for the activities of Internet pharmacies using more efficient technologies, including limiting their activities. 
Carrying out the research, several scientific methods were used. The methods of system-structural analysis, induction and deduction were used at all stages of the research in the study of the legal regulation of the sale of medicines in various countries through Internet pharmacies, the practice of its use, the state of illegal behavior in this area, analytical materials and scientific sources. The formal-logical method was used to study regulatory acts and international documents, the comparative-legal method was used to perform comparative analysis of the legal regulation of Internet pharmacies' activity, as well as the practice of its application in the countries of the European Union, the USA, Turkey, Ukraine, and some Arab states. It should be noted that in the EU member countries, due to single European economic and customs area and general regulation, the problems of Internet pharmacies are of the same nature. The content analysis method was implemented for studying journalistic materials and researching websites that offer distance selling, online ordering, and delivery of pharmaceutical products to a consumer in various ways.

Keywords: online pharmacies, digital marketing, digitalisation of pharmacy.

\section{Introduction}

Digital forms of pharmaceutical marketing aimed directly at the consumer have globalised in the era of free and open exchange of information (Mackey and Liang, 2013). As a result, marketing strategies in pharmacy activities are provided by digitalisation of pharmaceutical sales (Insights, 2011). Therefore, many online pharmacies operate worldwide today. Most of them work illegally, especially in countries with insufficient legal regulation of pharmaceutical activities. Illegal Internet pharmacies are well versed in digital marketing strategies, including search engine optimisation and social networks (Mackey \& Nayyar, 2016). It should also not be forgotten that in some countries, online trade of pharmaceutical products is performed through business entities that position themselves as a delivery service without specifying the seller of such product.

Meanwhile, a study of the literary sources revealed that in most EU countries, online pharmacies that operate within the legal framework are described as websites that comply with the laws of those countries in which the Internet pharmacy website functions, and the point of destination where pharmaceutical products are delivered to the final consumer (Fittler et al., 2013).

However, on the background of the growth of pharmacy digitalisation, there is an increase in the number of illegal Internet pharmacies that pose a threat to patients' health (Mackey \& Nayyar, 2016). Simultaneously, most online pharmacies, including those that operate legally, also violate the legislation on the procedure for dispensing medicines to patients. According to cyber security experts, $96 \%$ of all global online pharmacies operate outside the legal framework, illegally, without complying with regulatory documents (CSIP, 2016). 
Illegal online pharmacies that sell substandard drugs or poor-quality products pose a serious threat to patients. Still, even legitimate pharmacies can cause serious adverse health effects for users (Desa et al., 2015).

It is not only about violations of the procedure for dispensing pharmaceutical products but also about the sale of counterfeit drugs (Mackey \& Liang, 2013). Violations of the dispensing order of specific categories of pharmaceutical products and, as a result, inappropriate use of drugs are associated with the risk of increased resistance to antibiotics due to their improper use. At the same time, online trade of pharmaceutical products, online pharmacies, considering the processes of globalisation, is carried out not only within the borders of their country. Pharmaceutical website owners often change their electronic base between national jurisdictions (Cohen, 2004; Katsuki et al., 2015), while the jurisdiction of national regulatory authorities usually terminates at the borders of their countries (Tapscott \& Schepis, 2013).

According to the WHO, prevalence of counterfeit drugs through illegal Internet pharmacies is approximately $50 \%$ (World Health Organization, 2018). Meanwhile, patients are unaware of the risks of potential threats associated with buying drugs through online pharmacies and cannot distinguish between legal and illegal online pharmacies. Although in the EU countries, some measures have been taken to control the trade of medicines in compliance with the Directive on counterfeit drugs adopted by the European Council and the European Parliament (Directive 2011/62 / EU) (European Council, 2011).

The Directive introduces harmonised European measures to combat drug counterfeiting and to ensure safety of drugs, and strictly control their trade. These measures include mandatory use of a unique identifier and anti-tampering device on the outer packaging of medicines, the use of a common logo in the EU countries to denote legal Internet pharmacies, and others.

However, as the study showed, the measures taken were not enough to implement technological solutions for tracking circulation of medicines through the Internet pharmacy.

Therefore, medicines sold in some online pharmacies pose a severe public health risk, as the origin and quality of these medicines have not been determined, and patients usually use them beyond awareness and supervision of doctors.

Thus, the system of unique identification of outer packaging (barcoding) of medicines, which is used by most developed countries, including the EU countries, as well as the use of blockchain technology, in order to track drugs within one pharmaceutical network, is an insufficient means of ensuring safety of patients who use online pharmacies (Pashkov \& Soloviov, 2019).

The purpose of the article is to analyse activities of online pharmacies that actively use digital marketing methods, which leads to the danger of illegal circulation of pharmaceutical products, as well as to develop proposals for legal support of online pharmacies using more effective technologies, including limitation of their activities, considering experience of some countries. 
Within this research, the method of content analysis was used, namely, during the study in the summer of 2021, all legal online pharmacies were interviewed, with predetermined selected groups of pharmaceutical products according to international non-proprietary names and trademarks. When referring to the legal websites of pharmacy enterprises, a request was made to sell antibiotics without a prescription; none of the sites demanded a prescription from the authors of the study and agreed to deliver the prescription drug to the specified address. The method of systemic-structural analysis, induction, and deduction was used at all stages of the research while studying the problems of legal regulation of pharmaceutical products sale in various countries through Internet pharmacy, practice of its application, analytical materials, and scientific sources. The formal-logical method was used to study regulatory legal acts and international documents, the comparative-legal method was used to perform a comparative analysis of the legal regulation of Internet pharmacies activity, as well as the practice of its application in the countries of the European Union, the USA, Turkey, and Ukraine. The study found a surge in activity related to online pharmaceutical trade since 2018, following the announcement of the COVID-19 pandemic.

\section{Discussion and Results}

As a result of the COVID-19 pandemic, demand for various pharmaceuticals has increased, creating the possibility for illegal online pharmacies that have filled the gap in the pharmaceutical market, sometimes using counterfeit products (Fittler et al., 2021).

For example, in Hungary, during the pandemic 2020-2021, online pharmacies were inspected in terms of the sale of certain types of drugs. Patients accessed Internet pharmacy websites, most of which were illegal, accounting for almost half (53.3\%) of search engine results. Simultaneously, illicit pharmacies prevailed in number over legal ones. The vast majority $(77.7 \%)$ of the identified online pharmacies were knowingly illegal; $55.5 \%$ of them sold prescription drugs without a prescription (Miller et al., 2021). Meanwhile, prescription drugs are an essential part of effective healthcare. In addition, most patients began to use self-diagnosis and self-medication. An example is the use of certain groups of drugs for self-medication by patients, namely, increased demand, availability on the Internet, and availability for consumers of Ivermectin, an anthelmintic agent, without justified indications for SARS-CoV-2 (Miller et al., 2021).

It should be noted that sale of pharmaceutical products using digital technologies and through Internet pharmacy itself represents a significant breakthrough for pharmacy markets and is a positive step but requires the necessary legal support.

Online pharmacies first began to emerge back in the late 1990s. Today, the global market for online pharmacies based on the information from cyber security specialists is estimated at about $\$ 81.6$ billion, and according to forecasts, its growth may increase to $\$ 244$ billion by 2027 (Miller et al., 2021). This indicates that health-related technologies are evolving due to digitalisation of the healthcare system and prevalence of 
Vitalii Pashkov, Oleksii Soloviov, Andrii Harkusha. Digital Marketing:

Problems of Internet Pharmacies Legal Regulation

the Internet in everyday life. Digital forms of pharmaceutical marketing aimed directly at the consumer have globalised in the era of free and open exchange of information (Mackey \& Liang, 2013). Some researchers agree that the new direction of digitalisationrelated pharmaceutical services offered by online pharmacies is very attractive for most patients, especially those with disabilities (Miller et al., 2021). This provides the possibility of online orders within 24 hours, economic availability of most of the names of pharmaceutical products, and privacy issues. An example of the use of confidentiality is the increased demand for contraceptives through Internet pharmacy (Orizio et al., 2011). Simultaneously, the rapid expansion of the online pharmacy market was largely uncontrolled and accompanied by severe public health problems such as sale of drugs. Again, this regards the non-prescription dispensing of pharmaceutical products, which are distributed only by prescription, as well as inadequate provision of information to patients (Miller et al., 2021). However, the Internet differs from all other media in at least one crucial respect: it allows shoppers from all over the world to shop with relative anonymity on a 24/7 marketplace (Orizio et al., 2011). Internet pharmacies are an important phenomenon that continues to spread despite partial regulation due to internal difficulties associated with the intangible and fleeting nature of the Internet and its global dimension (Miller et al., 2021). It is challenging to estimate the number of online pharmacies and people shopping online, the volume of drugs sold, and revenues and profits generated from such a hidden business. Moreover, geographical distribution of the phenomenon seems to be very heterogeneous (Fittler et al., 2021).

Explaining the competitive cost of pharmaceutical products sold through Internet pharmacies, researchers associate it with low operating costs, advertising revenues, pressure to reduce costs due to comparative purchases, and/or high volume of sales (Orizio et al., 2011). In fact, this is a new kind of pharmaceutical market that can replace existing traditional pharmacies. Everything is more straightforward in countries where activities of Internet pharmacies are not regulated.

For instance, in Ukraine, under the Law of Ukraine On the Legal Regime of the State of Emergency, amendments were made to the Law of Ukraine On Protection of the Population from Infectious Diseases, and electronic trade of medicines was allowed, which was enshrined in the Resolution of the Cabinet of Ministers of Ukraine No. 220 dated 23.03.2020. According to this Resolution, changes were made to the Licensing Conditions for the implementation of economic activities for the production of medicines, wholesale and retail trade in medicines, import of medicines (except for active pharmaceutical ingredients), which were granted permission to carry out remote retail sales of medicines in the event of a quarantine. The right to carry out such activities was granted only to licensees who have a license to perform economic activities in the retail trade of medicines, who were also granted permission to organise and carry out delivery of medicines directly to consumers in compliance with the storage conditions for medicines determined by the manufacturer during their transportation, in particular, with the involvement of postal operators on contractual basis. This permit did not apply to 
Vitalii Pashkov, Oleksii Soloviov, Andrii Harkusha. Digital Marketing:

Problems of Internet Pharmacies Legal Regulation

the following categories of drugs: (1) drugs dispensed by prescription, other than those subject to reimbursement; (2) narcotic drugs, psychotropic substances, and precursors (according to the corresponding list); (3) potent and poisonous medicines; (4) medicinal products requiring special storage conditions.

Based on the law On Amendments to Article 19 of the Law of Ukraine On Medicines dated September 17, 2020, electronic retail trade in medicinal products received legislative consolidation for implementation of electronic retail trade in medicinal products.

In general, this Law complies with the European standards for electronic retail trade of medicines using information and communication systems in terms of creating a mechanism to counteract counterfeit medicine circulation, e.i, compliance with the provisions of Directive 2011/62/EU of the European Parliament and of the Council of 08.06.2011 amending Directive 2001/83/EU on the Community code for medicines for human use to prevent the introduction of counterfeit medicines into the legal supply chain (European Council, 2011).

However, licensing conditions for such activities were not accepted due to the opposition of certain representatives of the pharmaceutical business. In general, the reason for the appearance of such a document was the COVID-19 pandemic. Only when legal pharmacies tried to enter the online pharmaceutical market, it became obvious that such activity had long been occupied, divided, and developed according to its own rules, and legal pharmacies with their pricing policy had no control of the market. A negative touch of pricing in Ukrainian pharmacies is the widespread use of marketing contracts, in which a pharmacy purchases pharmaceutical products from a pharmaceutical manufacturer or distributor, subject to payment by the latter for marketing services for the so-called product promotion. It does not matter whether this product is a prescription product. This state of affairs is primarily due to monopolisation of pharmacy activities (Forman et al., 2006).

Considering the experience of the United States regarding activities of Internet pharmacies, it is necessary to recall the initiative of the National Association of Boards of Pharmacy (NABP) in 1999 to introduce a programme for verifying the websites of Internet pharmacies (Ivanitskaya et al., 2010).

Despite such measures, according to a 2015 NABP report, analysis of about 11,000 websites that sold prescription drugs online in the United States found $96 \%$ of online pharmacies not complying with the US law (NABP, 2015).

In this context, HR $6353\left(110^{\text {th }}\right)$ also has to be mentioned: Ryan Haight Online Pharmacy Consumer Protection Act of 2008 (United States Congress, 2008). According to this Law, on its home page Internet pharmacy must visibly and clearly display a statement that it meets the necessary requirements for the delivery, sale, or sale offer of controlled substances. The website has a declaration of conformity under this section.

Every online pharmacy must comply with the pharmacy licensing requirements of the Law in every state it operates in and in every state it delivers, distributes or dispenses in, or offers to deliver via the Internet, distribute or dispense controlled substances in accordance with the applicable licensing requirements established by the respective 
state. On every home page that the Internet pharmacy operates at, a page directly linked to it, where the hyperlink is visible or understandable, it must post, in a visible and clear manner, the following information about provision, distribution or dispensing of controlled substances in accordance with orders made on, through or on behalf of this website: (1) the name and address of the pharmacy as indicated on the Drug Enforcement Administration's pharmacy registration certificate; (2) the phone number and email address of the pharmacy; (3) the name, professional degree of the responsible pharmacist, as well as the telephone number by which the responsible pharmacist can be contacted; (4) a list of states in which the pharmacy is licensed to dispense controlled substances; (5) confirmation that the pharmacy is registered in accordance with this clause in order to deliver, distribute or dispense controlled substances via the Internet.

In the course of the study, applications were made for obtaining drugs necessary for treatment of bacterial infections, which are registered in Ukraine (the active ingredient is Tinidazole + Ciprofloxacin).

Applications were made to (1) LLC "Apteka nizkikh tsen", which has several partners united by one ultimate beneficiary of about 1000 pharmacies; (2) LLC "Sirius" - about 900 pharmacies; (3) LLC "Podorozhnik" - about 900 pharmacies; (4) LLC "Apteka dobrogo dnya" - about 800 pharmacies; (5) LLC "Med Service Group" - about 700 pharmacies; (6) LLC "Market Universal LTD" - about 700 pharmacies; (7) PJSC "Aptechnaya set' Farmatsiya" - about 500 pharmacies; (8) LLC "3 i" - about 500 pharmacies. These pharmacy enterprises ultimately shape the pharmaceutical policy in Ukraine and unite about $40 \%$ of the pharmacies in Ukraine. On all websites, drugs with the above active ingredient were available, and the product was offered with the delivery or self-pickup. None of the websites of these drugstores required prescription.

Simultaneously, representatives of these pharmacies, while dispensing drugs online, violated the legislation of Ukraine regarding the Rules for the Dispensing of Prescription Drugs, posing a threat the health of patients.

Implementation of the EU legislation set out in Directive No. 83 on distance selling of medicines did not lead to an improvement of OTC dispensing, the reason being that globalization of the new type of business is characterised by disregard for national jurisdiction. This makes it difficult for national government oversight bodies to track violations of online pharmacies. For the same reason, not only in the EU countries but also in the USA, as well as in Ukraine, there are similar problems. Although, from the point of view of Turkish officials, they have implemented the most complete control over the activities of Internet pharmacies, this approach is characterised by ignoring the principles of a market economy.

That is, in fact, a worldwide problem where the principles of the market economy are not violated, and the Internet is not blocked; activities of both legal and illegal Internet pharmacies are carried out with various violations in most cases, starting from the lack of legalisation of such pharmacies and ending with over-the-counter dispensing of pharmaceutical products. 
Vitalii Pashkov, Oleksii Soloviov, Andrii Harkusha. Digital Marketing:

Problems of Internet Pharmacies Legal Regulation

Globalisation of these processes, as well as ignorance of national jurisdictions by Internet pharmacies, indicates that this is a worldwide problem, regardless of the state of pharmaceutical market regulation. That is, websites of Internet pharmacies can be located anywhere in the world, and methods of delivery and accumulation of the required number of pharmaceutical products to further supply them to patients are of technical nature.

Further, websites providing information on the availability of medicinal products that contain the active ingredients Tinidazole + Ciprofloxacin were examined. During the study, several websites were found to have advertising information about medicinal products with these substances. For example, the Drugs Control website listed the drug's trade name and international non-proprietary name (Ciprofloxacin and Tinidazole). In this case, the information provided is sufficient for self-diagnosis.

Of interest are studies related to promoting and selling the prescription drug ALLUTOP through illegal Internet pharmacies (Gutorova, 2021). This is a solution for injection produced by the Romanian company "Biotechnos". The official distributor of this company is Biotechnos LLC (Register ID 41599490), which has a license to import and wholesale drugs, being the only authorised representative of the Romanian company Biotechnos in Ukraine that is a manufacturer of ALFLUTOP. At the time of the study, the drug was imported to Ukraine by this company in secondary packaging, where the inscription of the drug and other information in Ukrainian is placed on a yellow background.

A study of information from the Internet revealed a significant number of websites on which the drug "ALFLUTOP" was offered for sale to consumers, from which ten sites were selected where the drug was provided in secondary packaging with the appearance that differs from the one in which it is officially imported into Ukraine. That is an obvious sign of illegal pharmaceutical activity. At the same time, none of these websites had information about the existence of a license to sell (wholesale or retail) medicines.

According to the results of analysis, Internet pharmacies were divided into two groups; the first one includes Internet pharmacies on the website of which the consumer was frankly informed that the proposed medicines were imported into Ukraine with official permission directly from the EU or other countries. A characteristic feature of the illegal online pharmacies of this group was lack of any information about its location or landline phone number. Communication with the buyer was offered by mobile phone and/or using the feedback function provided directly on the website.

The second group of Internet pharmacies contained information for patients on their websites, which allegedly testified that the Internet sale of medicines is carried out in accordance with the legislation of Ukraine since such Internet sellers only help the consumer to find the necessary medication in the pharmacy, pay for them and deliver them to their destination. In contrast to the websites of Internet pharmacies of the first group, the consumer was provided with information about the landline phone number, and in some cases, the address of the location of the Internet pharmacy from which it was possible to pick up medicines. Some sites of this group contained messages that 
the delivery of medicines offered to a patient was an activity under a public offer agreement since no one can prohibit a person from buying medicines not personally but entrust this to his friend or relative.

The fact that the websites of both groups offered the drug "ALFLUTOP" illegally imported into Ukraine for sale is the evidence that Internet pharmacies of these groups perform illegal activities. Yet again, methods of selling drugs, payment, and delivery to the consumer are identical for them.

It should be noted that the pandemic has triggered changes in drug demand and access and has contributed to the development of self-diagnosis and self-medication practices among patients. Requirements to provide a prescription and the desire to use pharmaceutical products for self-medication create conditions for purchase of prescription drugs by patients in illegal online pharmacies (Mackey \& Liang, 2011; Mackey \& Nayyar, 2016). Basis for eliminating such risks for patients is placing restrictions on such websites. Most worrisome, however, is that due to unfair advertising as well as concerns about the declining availability of pharmaceutical products, patients suffering from continuing shortages may turn to the websites of illegal Internet pharmacies. That is, sale of pharmaceutical products through illegal Internet pharmacies is a means of promoting questionable therapeutic products for a wide range of treatments and diseases (Vida et al., 2020). A system arises when restrictions on access to specific groups of drugs contribute to the development of illegal Internet pharmacies (Mackey \& Liang, 2011).

Pharmaceutical advertising in digital marketing has a highly negative impact on patient self-diagnosis. Pharmaceutical companies spend vast amounts of money on advertising their brands on the Internet. Traditional media are often used to create or maintain brand awareness, reach a broader target audience, and digital ones - for more accurate targeting and outreach.

In the course of researching the information presented in the specialised journal Weekly Digest "Apteka" (Dmytryk, 2021), tendencies of the advertising market for pharmaceutical brands on the Internet were considered. In 2020, UAH 6.980 million were spent on advertising pharmaceutical products in Ukraine on the Internet. Nevertheless, according to the results of the first half of 2021, 454.3 million impressions of advertising of pharmaceutical products on the Internet were recorded in Ukraine. Among drug brands, the leaders in terms of the number of appearances on the Internet according to the results of the study period are Colikid, Nurofen, and Engystol.

Consequently, the way to counter digital marketing should be a decisive action by public authorities and professional associations to ensure control over circulation of pharmaceutical products. Tracking and traceability systems are increasingly being deployed as a technology solution to secure pharmaceutical supply chains. Turkey was the first country to implement a complete pharmaceutical traceability and control system throughout its regulated domestic supply chain (Parmaksiz et al., 2020). From a Turkish perspective, pharmaceutical policymakers should conduct systematic analysis of market, political, economic, technical, and legal factors before implementing any pharmaceutical 
Vitalii Pashkov, Oleksii Soloviov, Andrii Harkusha. Digital Marketing:

Problems of Internet Pharmacies Legal Regulation

traceability and control system. To achieve the intended results, the system must be consistent with the implementation goals (for example, combating fraud, reducing the number of counterfeit drugs, minimising shortages). Undoubtedly, total control of tracking circulation of pharmaceutical products requires additional resources and implementation of unpopular countermeasures.

\section{Conclusions}

The expanding market for illegitimate online pharmacies poses a global public health threat with potentially negative consequences for patient safety in all aspects of the healthcare system, as well as national economy. It is very difficult to estimate the number of online pharmacies and people who buy online, the volume of drugs sold, and the revenues and profits generated from such a hidden business. In addition to harm to patients, such online pharmacies, in cases of sale of counterfeit pharmaceutical products, harm economic relations and undermine confidence in the health care system in general.

Simultaneously, the recent surge in online drug sales represents a breakthrough in pharmaceutical markets, and COVID-19 further supports this trend. While online pharmacies were originally the domain of high-income countries, over the past decade, they have grown rapidly in low- and middle-income countries. On the one hand, online pharmacies pose a threat of over-the-counter dispensing of pharmaceutical products, including risks of dispensing counterfeit products. On the other hand, online pharmacies create conditions for expanding access of those patients to pharmaceutical products. This is especially true for patients who require regular medication for chronic diseases or have problems accessing traditional pharmacy services.

The regulation of this sector has not been able to keep up with these fast-growing, dynamic markets that easily operate across national borders and pose some regulatory challenges. Therefore, regulators need to pay more attention to ensure that they have the technical expertise to oversee it and adapt the regulatory process to take advantage of the opportunities e-pharmacy provides to improve traceability and transparency of drug sales.

Given the dynamism of e-pharmacy markets, countries need to quickly address lack of a regulatory framework. The first step for regulators would be to start a dialogue with larger, more compliant enterprises and work together to develop best practice guidelines and regulatory frameworks. Legal options may include tightening legal regulation, including restrictions on certain types of activities or expanded licensing, deletion of websites, which will simplify tracking of pharmaceutical products, and control over the activities of individual online pharmacies.

Among the methods of legal regulation, one can envisage accreditation procedures, domain restrictions, introduction of a national register of domain names for digital marketing subjects and websites. 
Vitalii Pashkov, Oleksii Soloviov, Andrii Harkusha. Digital Marketing:

Problems of Internet Pharmacies Legal Regulation

Achieving these changes requires increase in professionalism of specialists from state control bodies, as well as involvement of specialists in the field of information technology and e-commerce. In turn, transnational coordination of regulatory bodies of different countries remains relevant. Therefore, the most appropriate way to counter illegal digital marketing and its component, illegal activities of Internet pharmacies, is adoption of the international Convention On digital marketing and illegal activities of Internet pharmacies. The purpose of such document should be development of uniform rules for implementation of such activities, ways of decriminalising them and expanding national jurisdictions of the state control bodies of participating countries with the help of international mechanisms.

\section{Bibliography}

1. Ad Age Insights White Paper: Kantar Media. (2011). Pharmaceutical marketing. ur.gov.lv. http:// gaia.adage.com/images/bin/pdf/WPpharmmarketing_revise.pdf [rev. 27.08.2021].

2. Cohen, J. C. (2004). Public policy implications of cross-border Internet pharmacies. 13(3 Suppl):14-16.

3. CSIP, LegitScript. (2016).The Internet Pharmacy Market in 2016: Trends, Challenges, and Opportunities [Internet]. safemedsonline.org. http://www.safemedsonline.org/wp-content/ uploads/2016/01/The-Internet-Pharmacy-Market-in-2016.pdf [rev. 28.08.2021].

4. Desa, K., Chewning, B., Mott, D. (2015). Health care use amongst online buyers of medications and vitamins. ur.gov.lv. https://www.sciencedirect.com/science/article/abs/pii/ S1551741115000030?via\%3Dihub [rev. 25.08.2021].

5. Directive 2011/62/EU of the European Parliament and of the Council of 8 June 2011 amending Directive 2001/83/EC on the Community code relating to medicinal products for human use, as regards the prevention of the entry into the legal supply chain of falsified medicinal products. https://eurlex.europa.eu/legal-content/EN/TXT/?uri=celex\%3A32011L0062

6. Directive 2011/62/EU of the European Parliament and of the Council of 8 June 2011 amending Directive 2001/83/EC on the Community code relating to medicinal products for human use, as regards the prevention of the entry into the legal supply chain of falsified medicinal products (Text with EEA relevance). Official Journal of the European Union. 01.07.2011. https://ec.europa. eu/health/sites/default/files/files/eudralex/vol-1/dir_2011_62/dir_2011_62_en.pdf

7. Dmytryk, K. (2021). Telebachennia, radio, internet: reklama farmbrendiv u media. Pidsumky I pivrichchia 2021 r. Apteka Online UA. ur.gov.lv. https://www.apteka.ua/article/605910 [rev. 25.08.2021].

8. Epharmacy Market to Surpass \$244.0 Billion, Globally, by 2027 at a CAGR $17.0 \%$. Right ePharmacy, PlanetRx.com.Inc., Lloyds Pharmacy Ltd. (10-20-2021). Health \& Medicine. https://www. openpr.com/news/2435040/epharmacy-market-to-surpass-244-0-billion-globally-by-2027

9. Fittler, A., Bősze, G., Botz, L. (2013). Evaluating aspects of online medication safety in long-term follow-up of 136 Internet pharmacies: illegal rogue online pharmacies flourish and are long-lived. ur.gov.lv. https://pubmed.ncbi.nlm.nih.gov/24021777/ [rev.28.08.2021]

10. Fittler, A. et al. (2021). Effect of Infodemic Regarding the Illegal Sale of Medications on the Internet: Evaluation of Demand and Online Availability of Ivermectin during the COVID-19 Pandemic. ur.gov.lv. https://www.mdpi.com/1660-4601/18/14/7475 [rev. 28.08.2021]. 
Vitalii Pashkov, Oleksii Soloviov, Andrii Harkusha. Digital Marketing:

Problems of Internet Pharmacies Legal Regulation

11. Forman, R. F. et al. (2006). The Availability of Web Sites Offering to Sell Opioid Medications Without Prescriptions. ur.gov.lv. https://globalizationandhealth.biomedcentral.com/ articles/10.1186/1744-8603-9-45 [rev. 29.08.2021].

12. Gutorova, N. (2021). Legal remedies against black online market of medicines during COVID-19 Pandemic. Forum Prava. 2021, 68(3), 15-24. https:/forumprava.pp.ua/files/015-024-2021-3-FPGutorova_4.pdf [rev. 30.08.2021].

13. Gutorova, N., Pashkov, V., Soloviov, O. (2020) Legal means of ensuring competition in pharmacy. Wiadomości Lekarskie, LXXIII, 12, part 2, 2701-2708.

14. H.R. 6353 (110 th $)$ : Ryan Haight Online Pharmacy Consumer Protection Act of 2008. (2008). https://www.govtrack.us/congress/bills/110/hr6353/text

15. Internet Drug Outlet Identification Program Progress Report for State and Federal Regulators. (April 2015). National Association of Boards of Pharmacy. https://nabp.pharmacy/wpcontent/ uploads/2016/08/NABPIDOIReport_April2015.pdf

16. Ivanitskaya, L. et al. (2010). Dirt cheap and without prescription: how susceptible are young US consumers to purchasing drugs from rogue internet pharmacies? ur.gov.lv. https://www.ncbi. nlm.nih.gov/pmc/articles/PMC2885783/ [rev. 25.08.2021].

17. Katsuki, T., Mackey, T. K., Cuomo, R. (2015). Establishing a Link Between Prescription Drug Abuse and Illicit Online Pharmacies: Analysis of Twitter Data. ur.gov.lv. https://www.jmir. org/2015/12/e280/ [rev. 28.08.2021].

18. Liang, B. A., Mackey, T. K., Lovett, K. M. (2012). Suspect online sellers and contraceptive access. ur.gov.lv. https://www.contraceptionjournal.org/article/S0010-7824(12)00184-9/fulltext [rev. 28.08.2021].

19. Mackey, T. K., Liang, B. A. (2011). The global counterfeit drug trade: Patient safety and public health risks. Journal of Pharmaceutical Sciences. 100 (11, November), 4571-4579.

20. Mackey, T. K, Liang, B. A. (2013). Improving global health governance to combat counterfeit medicines: a proposal for a UNODC-WHO-Interpol trilateral mechanism. ur.gov.lv. https:// www.ncbi.nlm.nih.gov/pmc/articles/PMC4225602/ [rev. 28.08.2021].

21. Mackey, T. K., Liang, B. A. (2013). Pharmaceutical digital marketing and governance: illicit actors and challenges to global patient safety and public health. ur.gov.lv. https://globalizationandhealth. biomedcentral.com/articles/10.1186/1744-8603-9-45 [rev. 28.08.2021].

22. Mackey, T. K., Nayyar, G. (2016). Digital danger: a review of the global public health, patient safety and cybersecurity threats posed by illicit online pharmacies. ur.gov.lv. https://www.ncbi. nlm.nih.gov/pmc/articles/PMC5127424/ [rev. 28.08.2021].

23. Miller, R. et al. (2021). When technology precedes regulation: the challenges and opportunities of e-pharmacy in low-income and middle-income countries. ur.gov.lv. https://gh.bmj.com/content/6/5/e005405.abstract [rev. 28.08.2021].

24. National Association of Boards of Pharmacy. Digital Pharmacy. https://nabp.pharmacy/programs/accreditations-inspections/digital-pharmacy [rev. 28.08.2021].

25. Orizio, G. et al. (2011). Quality of Online Pharmacies and Websites Selling Prescription Drugs: A Systematic Review. ur.gov.lv. https://www.jmir.org/2011/3/e74// [rev. 28.08.2021].

26. Parmaksiz, K., Pisani, E., Kok, M. O. (2020). What Makes a National Pharmaceutical Track and Trace System Succeed? Lessons from Turkey. Global Health: Science and Practice. 8(3), 431-441. ur.gov.lv. https://www.ghspjournal.org/content/8/3/431 [rev. 25.08.2021]. 
Vitalii Pashkov, Oleksii Soloviov, Andrii Harkusha. Digital Marketing:

Problems of Internet Pharmacies Legal Regulation

27. Pashkov, V., Soloviov, O. (2019). Legal implementation of blockchain technology in pharmacy. Int. Conf. Society. Health. Welfare. 2018. ur.gov.lv. https://www.shs-conferences.org/articles/ shsconf/abs/2019/09/shsconf_shw2019_01027/shsconf_shw2019_01027.html [rev. 27.08.2021].

28. Tapscott, B. E., Schepis, T. S. (2013). Nonmedical Use of Prescription Medications in Young Adults. Analysis of Twitter Data. ur.gov.lv. https://www.ncbi.nlm.nih.gov/pmc/articles/ PMC4882925/ [rev. 29.08.2021].

29. Vida, R. G. et al. (2020). Developing a framework regarding a complex risk based methodology in the evaluation of hazards associated with medicinal products sourced via the internet. ur.gov.lv. https://www.ncbi.nlm.nih.gov/pmc/articles/PMC7783221/ [rev. 30.08.2021].

30. World Health Organization. (2018). Substandard and falsified medical products. Medicines: counterfeit medicines. ur.gov.lv. https://www.who.int/news-room/fact-sheets/detail/substandardand-falsified-medical-products [rev. 27.08.2021]. 